\title{
Adequate union rates for the treatment of acute proximal fifth metatarsal fractures
}

\author{
Q. G. H. Rikken ${ }^{1,2,3,4}$ (D) J. Dahmen ${ }^{2,3,4} \cdot$ N. C. Hagemeijer ${ }^{1}$ - I. N. Sierevelt ${ }^{2,3,4,6} \cdot$ G. M. M. J. Kerkhoffs ${ }^{2,3,4}$. \\ C. W. DiGiovanni ${ }^{1,5}$
}

Received: 17 March 2020 / Accepted: 14 May 2020 / Published online: 30 May 2020

(c) The Author(s) 2020

\begin{abstract}
Purpose To compare the bone healing, clinical, and return to daily activity outcomes after either surgical or conservative management of acute zone 1, 2, and 3 fifth metatarsal fractures.

Methods A literature search was performed to identify studies published from the earliest record to January 2019 using EMBASE (Ovid), MEDLINE via PubMed, CINAHL, and Web of Science. All articles assessing clinical outcomes of acute proximal fifth metatarsal fractures were included. Bone healing and clinical outcomes were thereafter calculated using a simplified pooling method.

Results Thirty-two articles comprising of a total of 1,239 fractures were included, of which one was a randomized controlled trial, seven were prospective studies, and 24 were retrospective studies. 627 zone 1 fractures demonstrated union rates of 93.2\% following conservative treatment and $95.1 \%$ following surgical treatment. Conservatively managed zone 1 fractures were displaced $49.5 \%$ of the time, compared to a rate of $92.8 \%$ for the surgically treated cases. For Jones' (zone 2) fractures, bone healing outcomes of conservative versus surgical treatment showed union rates of $77.4 \%$ versus $96.3 \%$, refracture rates of $2.4 \%$ versus $2.1 \%$, and mean time to union of 11.0 weeks versus 9.4 weeks, respectively. Only ten proximal diaphyseal (zone 3) fractures were reported, with a mean return to work of 8.2 weeks.

Conclusion Acute zone 1 fractures are preferably treated conservatively as similar union rates were found after both conservative and surgical management. In contradistinction, acute zone 2 fractures demonstrate higher union rates and faster time to union when treated surgically. The outcomes of acute zone 3 fractures are rarely reported in the literature, so treatment recommendations remain unclear. Further research of proximal fifth metatarsal fractures is warranted to provide more definitive conclusions, but current findings can aid surgeons during the shared clinical decision making process.
\end{abstract}

Level of evidence IV.

Keywords Fifth metatarsal $\cdot$ Fracture $\cdot$ Conservative $\cdot$ Surgery

Electronic supplementary material The online version of this article (https://doi.org/10.1007/s00167-020-06072-8) contains supplementary material, which is available to authorized users.

G. M. M. J. Kerkhoffs

g.m.kerkhoffs@amsterdamumc.nl

1 Foot and Ankle Research and Innovation Laboratory, Department of Orthopaedic Surgery, Massachusetts General Hospital, Harvard Medical School, Boston, USA

2 Department of Orthopaedic Surgery, Amsterdam Movement Sciences, Amsterdam UMC, University of Amsterdam, Meibergdreef 9, Amsterdam, The Netherlands

3 Academic Center for Evidence Based Sports Medicine (ACES), Amsterdam, The Netherlands
4 Amsterdam Collaboration for Health and Safety in Sports (ACHSS), International Olympic Committee (IOC) Research Center Amsterdam UMC, Amsterdam, The Netherlands

5 Foot and Ankle Service, Department of Orthopaedic Surgery, Massachusetts General Hospital, Newton-Wellesley Hospital, Harvard Medical School, Boston, MA, USA

6 Specialized Center of Orthopedic Research and Education (SCORE), Xpert Ortopedie, Amsterdam, The Netherlands 


\section{Introduction}

Acute fractures of the proximal fifth metatarsal are a common injury of the foot $[14,20,39]$. Currently, the choice between surgical or conservative treatment of these fractures is primarily based on anatomical location and degree of fracture displacement. Fractures of the proximal fifth metatarsal have been subdivided into three regions, as described by Lawrence and Botte [27]: tuberosity avulsion fractures (zone 1), Jones' fractures (zone 2) and, proximal diaphyseal fractures (zone 3). Even though controversy persists, the current trend in orthopaedic care has been to treat non-displaced zone 1 fractures primarily conservatively, to treat significantly displaced zone 1 fractures surgically, and to treat zone 2 and 3 fractures either conservatively or surgically depending on overall patient expectation and activity level [21, 23, $50,55]$. The first aim of this review was therefore to assess available literature to determine the bone healing outcomes following both surgical and conservative treatment of each anatomical zone of acute proximal fifth metatarsal fractures. A secondary aim of this study was to evaluate the clinical and return to activity related outcomes of each treatment strategy. The clinical utility of this work is aimed at providing better guidance for clinicians and patients during the shared decision making process.

\section{Material and methods}

The preferred reporting items for systematic reviews and meta-analyses statement (PRISMA) was used as a guideline for the present study [29]. The study protocol was prospectively registered in the PROSPERO registry for systematic reviews with registry number: CRD42019122682.

\section{Search strategy}

Studies from the earliest record (June 1902), until January 2019 were retrieved from EMBASE (Ovid), MEDLINE via PubMed, CINAHL, and Web of Science. The search strategy can be reviewed in the supplementary materials 2 .

\section{Eligibility criteria and study selection}

All randomized controlled trials (RCTs), controlled non-randomized trials, prospective-, and retrospective cohorts, comparative studies and case series that investigated conservative and/or surgical treatment of the acute proximal fifth metatarsal fracture types as proposed by Lawrence and Botte (see Fig. 1) were included. Case series were only included if they included 10 or more participants per treatment or

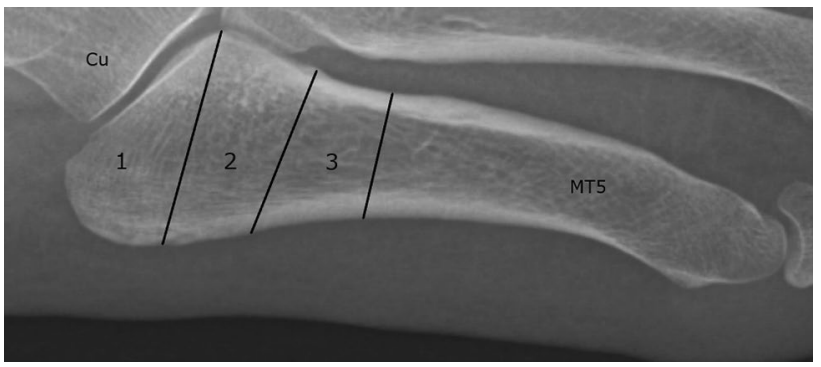

Fig. 1 Lawrence and Botte classification for proximal fifth metatarsal (MT5) fractures. zone 1: tuberosity avulsion fractures (1), zone 2: Jones' fractures (2), zone 3: proximal diaphyseal fractures (3)

Table 1 Exclusion criteria

Reoperation or non-union as primary treatment

No separate data for acute fractures per zone available

Stress fractures as primary fracture included or acute fracture data not separable

Review- and animal studies

Follow-up less than 12 weeks

fracture group. Furthermore, papers written in English, French, German and Dutch were eligible for inclusion. The exclusion criteria are listed in Table 1. Fracture acuteness was defined by each article's respective author. Additionally, Torg 1 fractures were included as acute fractures [22, 28]. No patient age, demographic or publication date restrictions were applied. Moreover, backward citation searching was used to find additional eligible articles. Authors were contacted by email if results were unclear for multiple anatomical locations or if results were combined between acute and stress fractures to enable separated datasets. If no response was recorded following two reminder emails, the respective author's paper was thereafter excluded. Two authors (Q.R. and J.D.) independently screened titles and abstracts, and full-text articles with predetermined inclusion and exclusion criteria as stated above, using Covidence (https://www.covid ence.org/home). Disagreement was resolved by an attempt to reach consensus. If no consensus was reached a third reviewer (N.H.) was decisive.

\section{Methodological quality}

Methodological quality was assessed by two independent reviewers (Q.R. and J.D.). Included articles were screened for bias using the Methodological Index for Non-Randomized Studies (MINORS) [46]. When no consensus was reached on the MINORS score, a third author (N.H.) was decisive. 


\section{Data extraction}

A standardized form was used to collect study characteristics and outcome measures. Data was only extracted if outcomes could be identifiable based on fracture type and/or anatomical location. Study characteristics retrieved included number of patients and fractures, age, gender, fracture location and type, mean follow-up time, percentage of physically active patients/athletes and study design. Bone healing outcomes included number of unions, number of combined delayed- and non-unions, number of refractures, time to union and the percentage of displaced tuberosity avulsion fractures $(>2 \mathrm{~mm})$. Healing- and non-healing rates were calculated as the percentage of radiographical (non/delayed)- unions, refractures of the total number of fractures per treatment modality. Refractures were, therefore, not considered as a healing/ treatment complication but an independent event. Time to return to activities and time to return to work were extracted as the same outcome variable representing a general return time to daily functioning. At last, all possible clinical outcome- or patient reported outcome measures were collected.

\section{Statistical and data analysis}

Heterogeneity of the included studies was assessed with an $I^{2}$ statistic and the results per study were visualized by means of a forest plot (eye-ball test) [16]. Due to high heterogeneity in study design it was decided that a formal meta-analysis was not possible. Therefore, a simplified pooling method was used to combine data from included studies for quantitative analysis. Pooled means and proportions were calculated by weighting the number of fractures per study for each specific zone or treatment modality (i.e. the bone healing rate of all surgically treated zone 2 fractures weighted by the number of fractures per individual study). The results for acute fractures were analysed for each Lawrence and Botte zone. Time units were converted either to weeks or months, depending on the outcome variable. A subgroup analysis of specific treatment modality was performed to assess the effect of independent treatments. No comparative synthesis was performed, as the indication to perform surgery is different and dependent on multiple, sometimes underreported, factors such as fracture displacement $[6,7,26]$. Ranges of reported pooled means encompassed the lowest and highest mean values from the included studies. Median values were transformed to mean values according to the formula from Hozo et al. [17]. Data analysis was carried out using Stata 15 (StataCorp LP, College Station, TX).

\section{Results}

\section{Article selection}

After screening, consensus was reached in all cases for article selection. The literature search yielded 2442 articles. After title and abstract screening and removal of duplicates, 217 articles were eligible for full-text screening and then 32 full articles were included for final analysis. Reasons for exclusion are listed in Fig. 2. One RCT, three prospective comparative (PC) studies, four prospective case series (PCS), five retrospective comparative studies (RC) and 19 retrospective case series (RCS) were included. Furthermore, one author provided additional data [37]. A total of 1239 proximal fifth metatarsal fractures were included in this review, with a mean age of 39.2 years. As reported in the supplementary materials 3 , nine different clinical outcome scores were reported in the included studies, of which the American Orthopaedic Foot \& Ankle Society (AOFAS) midfoot score [24] was most frequently reported and used for analysis.

\section{Methodological quality}

Consensus was reached between the reviewers regarding grading of methodological quality. Non-comparative studies scored an average of 7.2 points out of 16 (range: 3-12). Comparative studies had an average MINORS score of 15.4 out of 24 (range: 11-21). The individual MINORS score per study is displayed in supplementary materials 4 .

\section{Outcome measures}

\section{Tuberosity avulsion fractures (zone 1):}

For zone 1, 711 fractures were included from 19 studies [1, $3,4,6,11-13,15,23,25,26,32,37,45,50,52-54,58]$, of which $531(74.7 \%)$ fractures were managed conservatively and $180(25.3 \%)$ were managed surgically. Conservatively treated fractures were non-displaced in 267 (50.3\%) cases, displaced in $77(14.5 \%)$ cases, and unrecorded for 187 $(35.1 \%)$ cases. Surgically treated fractures were displaced in $167(92.8 \%)$ and non-displaced in 13 (7.2\%). An overview of the pooled patient characteristics and pooled treatment outcomes is shown in Table 2. Overall, conservative treatment showed a lower pooled bone healing rate and pooled mean time to union compared to surgical treatment of $91.0 \%$ versus $96.1 \%$ and 8.5 weeks versus 7.6 weeks, respectively (Table 2). Pooled results from secondary outcome measures can be seen in Table 2. The effect of displacement on bone 
Fig. 2 PRISMA flowchart of study selection

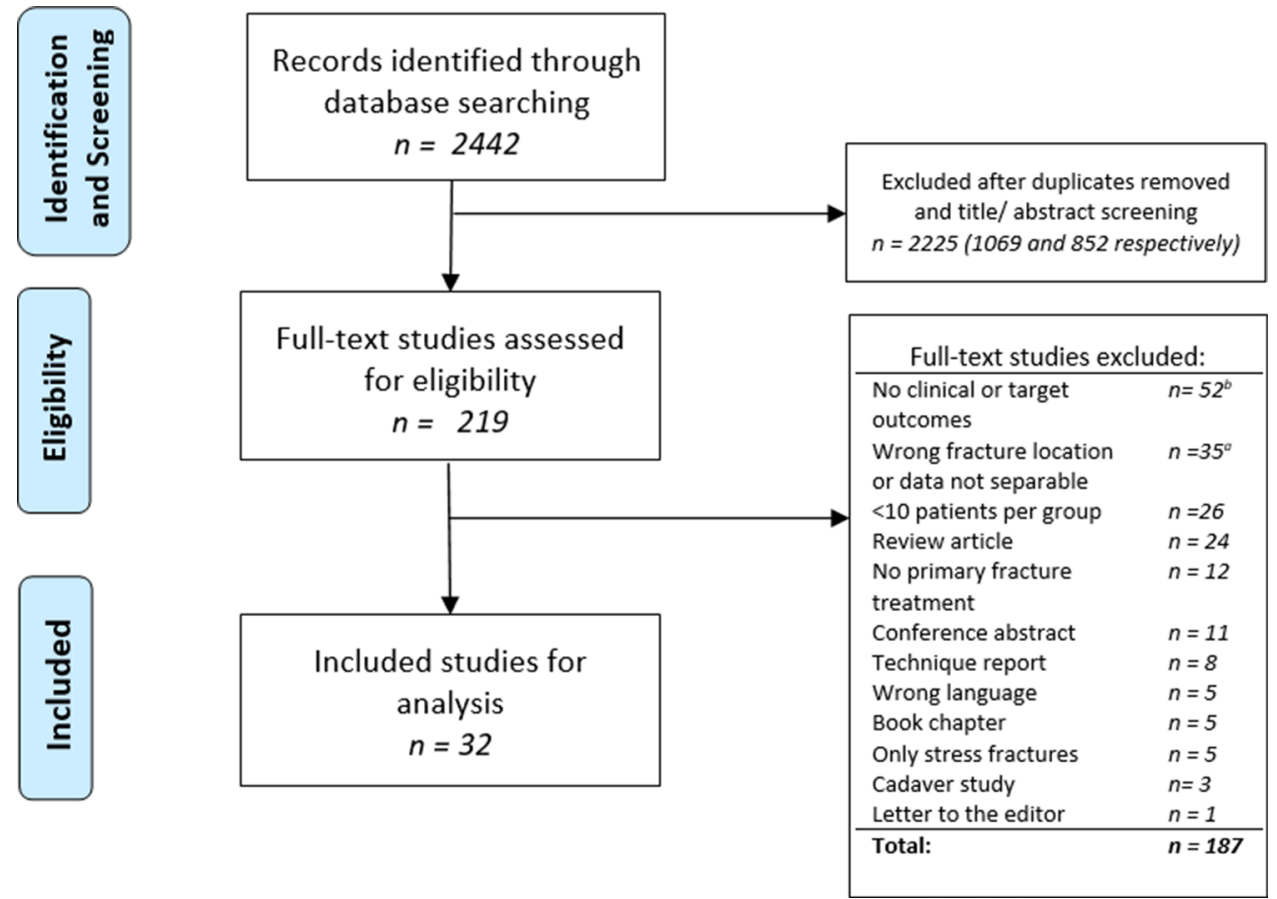

healing outcome showed that displaced tuberosity avulsion fractures had similar pooled bone union rates when treated surgically and conservatively (Table 3 ).

\section{Jones' fractures (zone 2)}

All pooled results for zone 2 fractures are listed in Table 4. 518 zone 2 fractures were included from 21 studies [1, 3-7, $12,19,22,25,30,32,34,36,37,41,44,49-51,56]$, of which $318(61.4 \%)$ fractures received conservative treatment and 200 (38.6\%) received surgical treatment. The pooled patient characteristics and pooled treatment outcomes of zone 2 fractures are presented in Table 4. Pooled bone healing outcomes of conservative versus surgical treatment showed union rates of $77.4 \%$ versus $96.3 \%$, refracture rates of $2.4 \%$ versus $2.1 \%$, and mean time to union of 11.0 weeks versus 9.4 weeks, respectively. Pooled secondary outcomes are displayed in Table 4.

\section{Proximal diaphyseal fractures (zone 3)}

Ten acute zone 3 fractures from a single case series were found through the literature search (also see supplementary materials 1), with the patients having a mean age of 57 years and follow-up of 15 months (range 12-24) [4]. Individual study characteristics can be viewed in the supplementary materials 1 . In this series all patients were treated conservatively and no bone healing outcomes were presented. Six patients were treated with casting and reported a return to work at mean 8.0 weeks and a AOFAS score of 85 . The functional (shoe) group, consisting of four patients, returned to work at mean time of 8.5 weeks and had a mean AOFAS score of 83 .

\section{Discussion}

The most notable finding of this study was that union rates for tuberosity avulsion fractures were found to be independent of both initial treatment choice and degree of fracture displacement. Non-displaced zone 1 fractures demonstrated particularly uncomplicated union rates following non-operative management. Outcome analysis of displaced zone 1 fractures, however, also demonstrated similar union rates for surgical and conservative treatment, albeit with a more limited dataset. In contradistinction, both higher union rates and faster times to union were found following the surgical management of zone 2 fractures when compared to conservative treatment methods. Acute proximal diaphyseal (zone 3 ) fractures appear to be a rare occurrence in the literature, and therefore an optimized treatment algorithm cannot be determined at this time.

\section{Tuberosity avulsion (zone 1) fractures}

When disregarding fracture displacement, zone 1 fractures were found to have a lower pooled healing rate when treated conservatively. However, multiple factors contribute to this finding. First, fracture displacement is an important treatment indication for zone 1 fractures as displaced fractures 


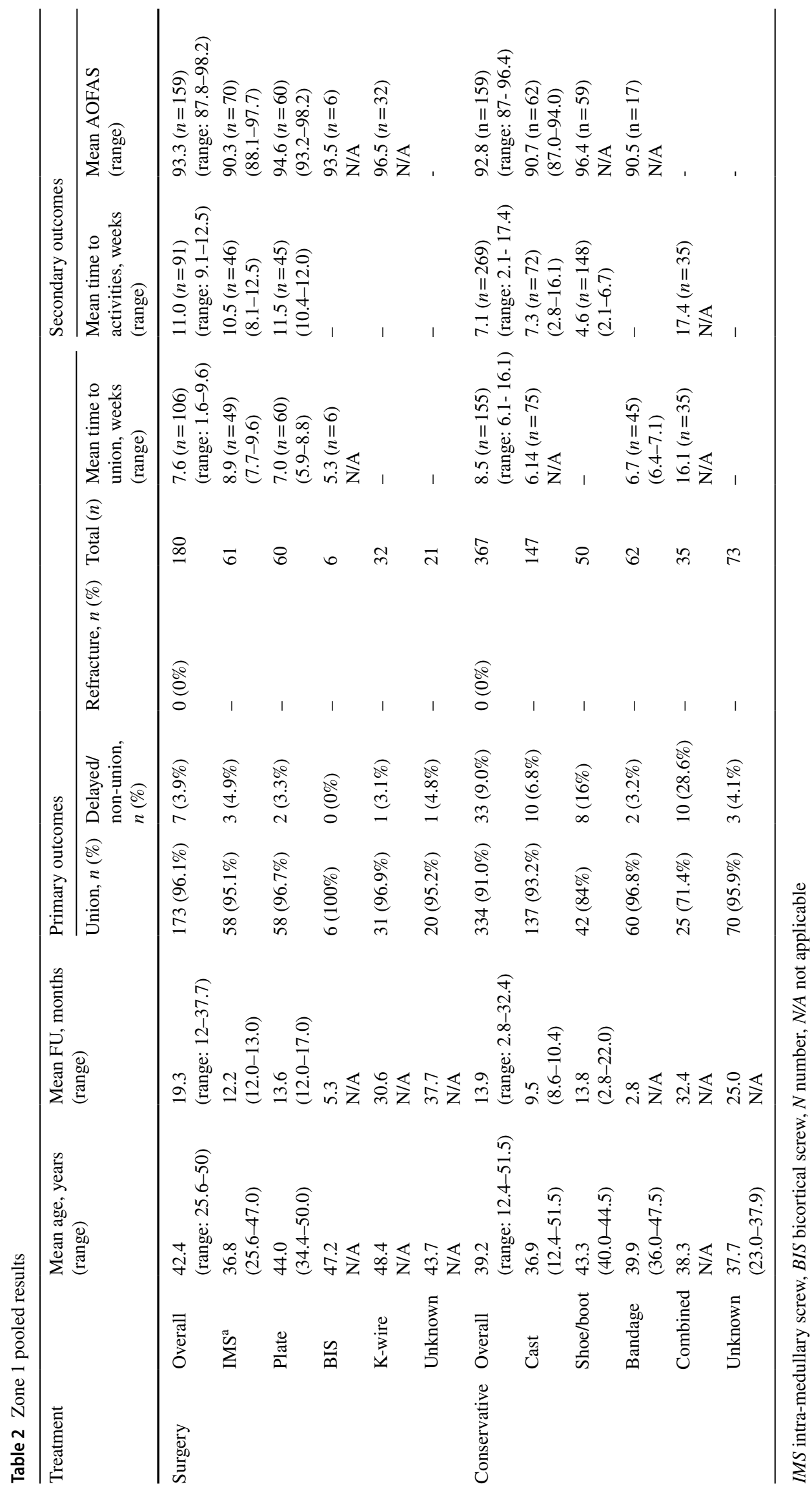


Table 3 Pooled weighted bone union outcomes displaced and nondisplaced fractures zone 1

\begin{tabular}{llllll}
\hline & & Union & Non/delayed-union & Total & $\begin{array}{l}\text { Time to union } \\
\text { (weeks), range }\end{array}$ \\
\hline ND & S & - & - & - & - \\
& C & $33(100 \%)$ & $0(0 \%)$ & 33 & - \\
D & S & $92(94.8 \%)$ & $5(5.2 \%)$ & 97 & $8.3(5.3-9.6)$ \\
& C & $48(92.3 \%)$ & $4(7.7 \%)$ & 52 & - \\
\hline
\end{tabular}

Only included studies with separate data for displaced or non-displaced fractures

$S$ surgery, $C$ conservative, $D$ displaced ( $>2 \mathrm{~mm}$ ), $N D$ non-displaced $(<2 \mathrm{~mm})$

tend to be fixed surgically. Naturally, the healing rate of non-displaced fractures might differ, as treatment indications could vary among different orthopaedic institutions, which may also influence the healing rate of conservative treatment. Secondly, the averaged low overall bone healing rate following conservative treatment in this review may in part be attributable to the low healing rate $(71.4 \%)$ of a single study included [25]. Possible factors affecting bone union in this series could be the high percentage of displaced fractures, the relatively high number of older patients, and a lack of standardization amongst treatment regimens. Thirdly, this review pooled the outcomes of both athletes and nonathletes, the former of whom were more likely to have been treated surgically and thus introduced possible selection bias $[12,26,53]$. Most zone 1 fractures were non-displaced and managed conservatively in both athletes and non-athletes, however, with high union rates and few complications that are consistent with current literature [42, 43, 50, 52]. Nondisplaced tuberosity avulsion fractures should therefore be treated conservatively. This is in line with a systematic review article by Kerkhoffs et al. who reviewed the literature in 2012 and similarly found favourable healing rates and return to activities after conservative treatment [21].

For displaced zone 1 fractures the pooled mean healing rate was found not to be clinically different. It should be noted, however, that union data for this analysis was only available for a small number of patients, resulting in a limited assessment. Therefore, these results should be interpreted with caution and comparative research is warranted as authors have cited fracture displacement of more than $2 \mathrm{~mm}$ as a reason for surgical intervention with excellent results $[6,11,23,26,32,53,54,58]$. This can partly be explained by the difficulty of stable anatomical reduction of the avulsion fragment without fixation due to tendinous traction of the peroneus brevis, peroneus tertius, and lateral plantar aponeurosis [48]. A single study by $\mathrm{Wu}$ et al. included in this systematic review directly compared surgical and conservative therapy, favouring surgery for return to activities and AOFAS scores [53]. Unfortunately, however, none of the primary outcomes of the present review were assessed in the aforementioned study.

\section{Jones' (zone 2) fractures}

No clear consensus exists regarding optimal treatment of zone 2 fractures [21]. Traditionally, surgical treatment was primarily advised for athletes who desired faster return to sport, but this has now been increasingly advised for the non-athletic population as well $[36,41]$. While the present review did not stratify between athletes and non-athletes, an overall higher union rate and faster time to union were identified with the surgically treated group.

Jones' fractures are prone to stress forces and have a poor blood supply leading to an impaired healing tendency [8, 47]. Ekstrand et al. found no clear correlation between the Torg classification and the injury circumstances (i.e. injury due to trauma or overuse) [12]. Ekstrand concluded that at primary presentation most fractures were registered as traumatic, even though half were found to be stress related per radiograph. Certain fractures that presented as acute may have occurred based on underlying stress phenomena, thereby incorrectly suggesting an acute fracture. Conceivably, a subset of the acute zone 2 fractures in this systematic review did involve a repetitive component but were considered acute due to their clinical presentation. This may have negatively affected the pooled union rate of conservative treatment, however, because stress fractures have been observed to have higher union rates and shorter union times when treated surgically $[7,12,31,33]$. An example of this is the included RCT in this review which randomized allocated active military staff to either the casting or intra-medullary screw (IMS) treatment group [36]. Screw-fixation showed a significantly higher bone healing rate and a shorter time to union than casting. Additionally, early surgical intervention resulted in a lower incidence of non-unions, delayed unions and refractures as well as a faster return to activities. It should be noted, however, that the military population remains at inherent risk of repetitive microtrauma as part of the pathoaetiology of their fracture outcome. Further research is necessary to stratify between the genuinely acute, sub-acute (where there is a potential stress riser component), and chronic stress related fractures. Additionally, biomechanical studies are warranted to further elaborate on the processes underlying sub-acute and stress fractures.

Surgical management for the acute zone 2 fractures seems justified when considering the superior bone healing outcomes. Treatment providers, however, should consider inherent complications related to surgical procedures [7, 9, $36,41]$. Surgical treatment may become the preferred choice of treatment depending on patient factors such as age, BMI, social- and work status and patient choice. Even though outcomes seem less favourable after conservative treatment, 


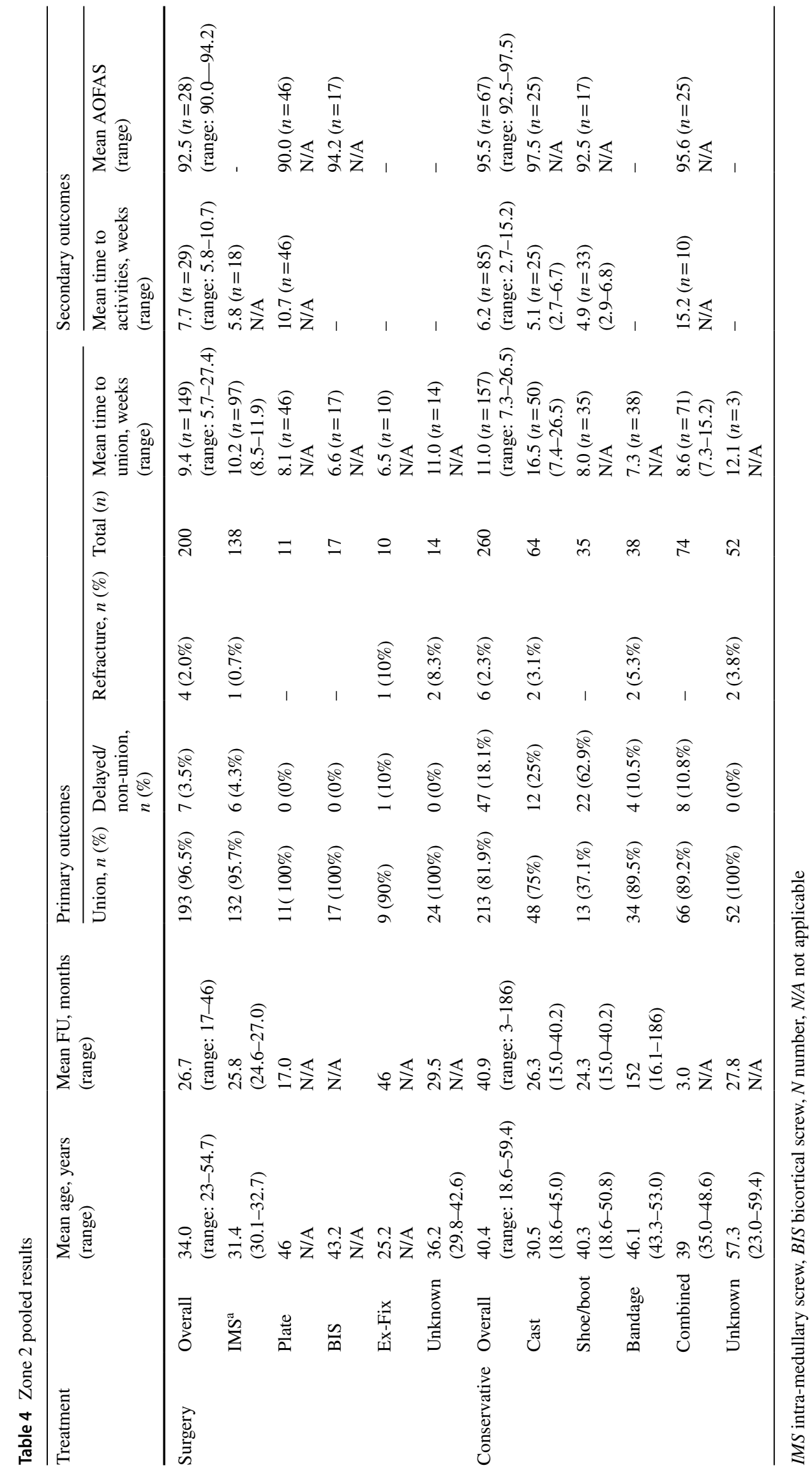


its non-invasiveness and the fact that there is low quality evidence supporting surgical treatment makes it justifiable as treatment for zone 2 fractures, especially in cases where there is no suspicion for repetitive trauma.

\section{Proximal tuberosity fractures}

Zone 3 fractures are generally considered stress fractures that can be treated both surgically and conservatively $[7$, $10,25,35,38,40]$. Only one case series of acute fractures was found with comparable outcomes of conservative treatment for zone 1 and 2 [4]. However, case reports by Zelko et al. [57] and Arangio et al. [2] reported varying results of their primarily surgically treated patients. Traditionally, the "Jones fracture" occurs in both zone 2 and 3, as described in the original 1902 article [18]. Conventional orthopaedic literature describes a Jones fracture as a fracture at the proximal diaphysis and metaphysis junction of the fifth metatarsal without distal extension beyond the fourth to fifth intermetatarsal articulation [7, 27, 36]. The varying fractures termed "Jones fractures" could potentially explain the underrepresentation of acute zone 3 fractures in the literature. Acute zone 3 fractures are rarely reported in the literature, prompting a call for more research into these fractures.

\section{Methodological considerations}

The outcomes of this systematic review must be interpreted within the context of its design. First, few high-level articles were included in this study as was shown by the low MINORS score of the body of included articles. Therefore, interpretation of the results in the present systematic review must be done with caution. Additionally, only one zone 1 study, and three zone 2 studies directly compared surgery with conservative therapy, making a formal statistical comparison by meta-analysis methodologically unfit. A simplified pooling technique was therefore used, allowing a large body of articles to be included which could introduce bias as a result of including varying study designs and patients populations. Performing a comparative synthesis for the present study was deliberately avoided because treatment indications for these fractures differed within this body of literature. Therefore, it should be noted that the clinical outcomes of this study have to be interpreted with caution and should not be used for treatment decisions for individual patients.

Second, this review only included acute fractures of the proximal fifth metatarsal, as stress fractures have an inherent tendency for impaired healing. There seems, however, to be no uniform definition that clearly stratifies acute-from stress fractures. This might have had an effect on the results of this study as it might have been possible that patients that actually had a stress fracture were included in this systematic review, thus biasing results.

\section{Conclusion}

Non-displaced acute tuberosity (zone 1) avulsion fractures are preferably treated conservatively given comparable union rates and clinical outcomes were found, regardless of chosen management, and fracture healing is typically uncomplicated. Ideal management of displaced zone 1 fractures remains unclear due to the small number of cases identified, although available evidence suggests that both conservative and surgical treatment demonstrate comparable union rates. Acute zone 2 fractures were found to have higher union rates and faster time to union when managed surgically, which the current literature supports as the treatment of choice for all such injuries. Acute zone 3 fractures continue to be rarely reported in the literature, so treatment outcomes remain insufficiently documented and thus preclude any formal management recommendation. Higher level of evidence research on proximal fifth metatarsal fractures will be necessary to provide more definitive conclusions.

Acknowledgements The authors would like to thank Lisa Philpotts from the MGH Treadwell library for her assistance with the literature search.

Author contributions QR, JD, NH and IS have made substantial contributions to conception and design, acquisition of data, analysis and interpretation of data, and have been involved in drafting the manuscript. GK and CD have been involved in revising the manuscript, critically for important intellectual content, and have given final approval of the version to be published.

Availability of data and material Not applicable.

\section{Compliance with ethical standards}

Conflict of interest C.W. DiGiovanni reports board membership of AOFAS, FAI, FAO and Eur J FAS. No other authors reported receiving funding for this study or any other conflict of interest.

Funding No funding was received for this study.

Ethical approval Not applicable.

Consent to participate/publish Not applicable.

Open Access This article is licensed under a Creative Commons Attribution 4.0 International License, which permits use, sharing, adaptation, distribution and reproduction in any medium or format, as long as you give appropriate credit to the original author(s) and the source, provide a link to the Creative Commons licence, and indicate if changes were made. The images or other third party material in this article are included in the article's Creative Commons licence, unless indicated otherwise in a credit line to the material. If material is not included in the article's Creative Commons licence and your intended use is not permitted by statutory regulation or exceeds the permitted use, you will need to obtain permission directly from the copyright holder. To view a copy of this licence, visit http://creativecommons.org/licenses/by/4.0/. 


\section{References}

1. Van AJ, Berli MC, Noger M, Gambirasio R, Fritschy D (2007) Traitement symptomatique des fractures non déplacées de la base du cinquième métatarse: étude prospective. Rev Med Suisse 3:12-14

2. Arangio GA (1983) Proximal diaphyseal fractures of the fifth metatarsal (Jones' fracture): two cases treated by cross-pinning with review of 106 cases. Foot Ankle 3:293-296

3. Baumbach SF, Prall WC, Kramer M, Braunstein M, Böcker W, Polzer H (2017) Functional treatment for fractures to the base of the 5th metatarsal-influence of fracture location and fracture characteristics. BMC Musculoskelet Disord 18:534

4. Biz C, Zamperetti M, Gasparella A, Dalmau-Pastor M, Corradin M, De Guttry G, Ruggieri P (2017) Early radiographic and clinical outcomes of minimally displaced proximal fifth metatarsal fractures: cast vs functional bandage. Muscles Ligaments Tendons J 7:532-540

5. Chee-Kidd C, Vivek AS (2009) Is nonoperative treatment still indicated for Jones fracture? Eur J Trauma Emerg Surg $35: 407-410$

6. Choi JH, Lee KT, Lee YK, Lee JY, Kim HR (2012) Surgical results of zones $i$ and ii fifth metatarsal base fractures using hook plates. Orthopedics 36:e71-e74

7. Chuckpaiwong B, Queen RM, Easley ME, Nunley JA (2008) Distinguishing Jones and proximal diaphyseal fractures of the fifth metatarsal. Clin Orthop Relat Res 466:1966-1970

8. Dameron TB (1975) Fractures and anatomical variations of the proximal portion of the fifth metatarsal. J Bone Joint Surg Am 57:788-792

9. Dean BJF, Kothari A, Uppal H, Kankate R (2012) The Jones fracture classification, management, outcome, and complications. Foot Ankle Spec 5:256-259

10. Delee JC, Evans JP, Julian J (1983) Stress fracture of the fifth metatarsal. Am J Sports Med 11:349-353

11. Egol K, Walsh M, Rosenblatt K, Capla E, Koval KJ (2007) Avulsion fractures of the fifth metatarsal base: a prospective outcome study. Foot Ankle Int 28:581-583

12. Ekstrand J, van Dijk CN (2013) Fifth metatarsal fractures among male professional footballers: a potential career-ending disease. Br J Sports Med 47:754-758

13. Gray AC, Rooney BP, Ingram R (2008) A prospective comparison of two treatment options for tuberosity fractures of the proximal fifth metatarsal. Foot 18:156-158

14. Hasselman CT, Vogt MT, Stone KL, Cauley JA, Conti SF (2003) Foot and ankle fractures in elderly white woman. Incidence and risk factors. J Bone Joint Surg Am 85:820-824

15. Herrera-Soto JA, Scherb M, Duffy MF, Albright JC (2007) Fractures of the fifth metatarsal in children and adolescents. J Pediatr Orthop 27:427-431

16. Higgins JPT, Thompson SG, Deeks JJ, Altman DG (2003) Measuring inconsistency in meta-analyses. BMJ 327:557-560

17. Hozo SP, Djulbegovic B, Hozo I (2005) Estimating the mean and variance from the median, range, and the size of a sample. BMC Med Res Methodol 5:13

18. Jones R (1902) I. Fracture of the base of the fifth metatarsal bone by indirect violence. Ann Surg 35:697-700

19. Josefsson PO, Karlsson M, Redlund-Johnell I, Wendeberg B (1994) Closed treatment of jones fracture: good results in 40 cases after 11-26 years. Acta Orthop 65:545-547

20. Kane JM, Sandrowski K, Saffel H, Albanese A, Raikin SM, Pedowitz DI (2015) The epidemiology of fifth metatarsal fracture. Foot Ankle Spec 8:354-359
21. Kerkhoffs GM, Versteegh VE, Sierevelt IN, Kloen P, van Dijk CN (2012) Treatment of proximal metatarsal V fractures in athletes and non-athletes. Br J Sports Med 46:644-648

22. Khan W, Agarwal M, Warren-Smith C (2005) Management of fractures of the base of the fifth metatarsal distal to the tuberosity. Foot 15:141-145

23. Kim JB, Song IS, Park BS, Ahn CH, Kim CU (2017) Comparison of the outcomes between headless cannulated screw fixation and fixation using a locking compression distal ulna hook plate in fracture of fifth metatarsal base. J Foot Ankle Surg $56: 713-717$

24. Kitaoka HB, Alexander IJ, Adelaar RS, Nunley JA, Myerson MS, Sanders M (1994) Clinical rating systems for the ankle-hindfoot, midfoot, hallux, and lesser toes. Foot Ankle Int 15:349-353

25. Konkel KF, Menger AG, Retzlaff SA (2005) Nonoperative treatment of fifth metatarsal fractures in an orthopaedic suburban private multispeciality practice. Foot Ankle Int 26:704-707

26. Koslowsky TC, Gausepohl T, Mader K, Heck S, Pennig D (2010) Treatment of displaced proximal fifth metatarsal fractures using a new one-step fixation technique. J Trauma 68:122-125

27. Lawrence SJ, Botte MJ (1993) Jones' fractures and related fractures of the proximal fifth metatarsal. Foot Ankle 14:358-65

28. Lee KT, Park YU, Young KW, Kim JS, Kim JB (2011) Surgical results of 5th metatarsal stress fracture using modified tension band wiring. Knee Surg Sport Traumatol Arthrosc 19:853-857

29. Liberati A, Altman DG, Tetzlaff J, Mulrow C, Gøtzsche PC, Ioannidis JPA, Clarke M, Devereaux PJ, Kleijnen J, Moher D (2009) The PRISMA statement for reporting systematic reviews and meta-analyses of studies that evaluate health care interventions: explanation and elaboration. PLoS Med 6:e1000100

30. Lombardi CM, Connolly FG, Silhanek AD (2004) The use of external fixation for treatment of the acute jones fracture: a retrospective review of 10 cases. J Foot Ankle Surg 43:173-178

31. Low K, Noblin JD, Browne JE, Barnthouse CD, Scott AR (2004) Jones fractures in the elite football player. J Surg Orthop Adv $13: 156-160$

32. Mahajan V, Chung HW, Suh JS (2011) Fractures of the proximal fifth metatarsal: percutaneous bicortical fixation. Clin Orthop Surg 3:140

33. Mallee WH, Weel H, van Dijk CN, van Tulder MW, Kerkhoffs GM, Lin C-WC (2015) Surgical versus conservative treatment for high-risk stress fractures of the lower leg (anterior tibial cortex, navicular and fifth metatarsal base): a systematic review. Br J Sports Med 49:370-376

34. Marecek GS, Earhart JS, Croom WP, Merk BR (2016) Treatment of acute Jones fractures without weightbearing restriction. J Foot Ankle Surg 55:961-964

35. Massada MMT de O, Pereira MANPG, de Sousa RJG, Costa PG, Massada JL da R (2012) Intramedullary screw fixation of proximal fifth metatarsal fractures in athletes. Acta Ortop Bras 20:262-265

36. Mologne TS, Lundeen JM, Clapper MF, O’Brien TJ (2005) Early screw fixation versus casting in the treatment of acute Jones fractures. Am J Sports Med 33:970-975

37. Monteban P, van den Berg J, van Hees J, Nijs S, Hoekstra H (2018) The outcome of proximal fifth metatarsal fractures: redefining treatment strategies. Eur J Trauma Emerg Surg 44:727-734

38. Pecina M, Bojanic I, Smoljanovic T, Ivkovic A, Mirkovic M, Jelic M (2011) Surgical treatment of diaphyseal stress fractures of the fifth metatarsal in competitive athletes: long-term follow-up and computerized pedobarographic analysis. J Am Podiatr Med Assoc 101:517-522

39. Petrisor BA, Ekrol I, Court-Brown C (2006) The epidemiology of metatarsal fractures. Foot Ankle Int 27:172-174 
40. Popovic N, Jalali A, Georis P, Gillet P (2005) Proximal fifth metatarsal diaphyseal stress fracture in football players. Foot Ankle Surg 11:135-141

41. Portland G, Kelikian A, Kodros S (2003) Acute surgical management of Jones' fractures. Foot Ankle Int 24:829-833

42. Quill GE (1995) Fractures of the proximal fifth metatarsal. Orthop Clin N Am 26:353-361

43. Richli W, Rosenthal D (1984) Avulsion fracture of the fifth metatarsal: experimental study of pathomechanics. Am J Roentgenol 143:889-891

44. Seitz WH, Grantham SA (1985) The Jones' fracture in the nonathlete. Foot Ankle 6:97-100

45. Shahid MK, Punwar S, Boulind C, Bannister G (2013) Aircast walking boot and below-knee walking cast for avulsion fractures of the base of the fifth metatarsal: a comparative cohort study. Foot Ankle Int 34:75-79

46. Slim K, Nini E, Forestier D, Kwiatkowski F, Panis Y, Chipponi J (2003) Methodological index for non-randomized studies (minors): development and validation of a new instrument. ANZ J Surg 73:712-716

47. Smith JW, Arnoczky SP, Hersh A (1992) The intraosseous blood supply of the fifth metatarsal: implications for proximal fracture healing. Foot Ankle 13:143-152

48. Theodorou DJ, Theodorou SJ, Kakitsubata Y, Botte MJ, Resnick D (2003) Fractures of proximal portion of fifth metatarsal bone: anatomic and imaging evidence of a pathogenesis of avulsion of the plantar aponeurosis and the short peroneal muscle tendon. Radiology 226:857-865

49. Torg JS, Balduini FC, Zelko RR, Pavlov H, Peff TC, Das M (1984) Fractures of the base of the fifth metatarsal distal to the tuberosity. Classification and guidelines for non-surgical and surgical management. J Bone Joint Surg Am 66:209-214

50. Vorlat P, Achtergael W, Haentjens P (2007) Predictors of outcome of non-displaced fractures of the base of the fifth metatarsal. Int Orthop 31:5-10
51. Waverly BJ, Sorensen MD, Sorensen TK (2018) Early weightbearing protocol in operative fixation of acute Jones fractures. J Foot Ankle Surg 57:489-493

52. Wiener BD, Linder JF, Giattini JFG (1997) Treatment of fractures of the fifth metatarsal: a prospective study. Foot Ankle Int 18:267-269

53. Bin WuG, Li B, Yang YF (2018) Comparative study of surgical and conservative treatments for fifth metatarsal base avulsion fractures (type I) in young adults or athletes. J Orthop Surg 26:1-5

54. Xie L, Guo X, Zhang SJ, Fang ZH (2017) Locking compression plate distal ulna hook plate fixation versus intramedullary screw fixation for displaced avulsion fifth metatarsal base fractures: a comparative retrospective cohort study. BMC Musculoskelet Disord 18:1-6

55. Yates J, Feeley I, Sasikumar S, Rattan G, Hannigan A, Sheehan E (2015) Jones fracture of the fifth metatarsal: Is operative intervention justified? A systematic review of the literature and metaanalysis of results. Foot 25:251-257

56. Yoho RM, Vardaxis V, Dikis J (2015) A retrospective review of the effect of metatarsus adductus on healing time in the fifth metatarsal jones fracture. Foot 25:215-219

57. Zelko RR, Torg JS, Rachun A (1979) Proximal diaphyseal fractures of the fifth metatarsal-treatment of the fractures and their complications in athletes. Am J Sports Med 7:95-101

58. Zhao J, Yu B, Xie M, Huang R, Xiao K (2017) Surgical treatment of zone 1 fifth metatarsal base fractures using the locking compression plate distal ulna hook plate. J Am Podiatr Med Assoc 107:369-374

Publisher's Note Springer Nature remains neutral with regard to jurisdictional claims in published maps and institutional affiliations. 